\title{
Chalmers, Beverley. Birth, Sex and Abuse: Women's Voices Under Nazi Rule. Tolworth, Surrey, UK: Grosvenor House Publishing Ltd, 2015.
}

\section{Reviewed by Tamala Malerk, University of South Florida, Tampa, Florida, USA.}

Beverly Chalmers considers the experiences of women under Nazism using a "broad social and psychological perspective" in Birth, Sex and Abuse: Women's Voices Under Nazi Rule (2). Chalmers is well equipped for such an undertaking; she has two doctoral degrees, one a Doctoral of Science in Medicine and a PhD in Psychology, which allows her to aptly demonstrate the plights and experiences of Jewish women and non-Jewish women during the Nazi regime.

In the Introduction of Birth, Sex and Abuse, Chalmers broadly argues "that targeting reproduction and sexuality was a central theme underlying many aspects of Nazi policy through both 'positive eugenics...' as well as "negative eugenics," to "further illuminate the role played by the medical profession, in particular, in manipulating reproductive and sexual lives to achieve the Nazi goals," to "integrate the widely dispersed evidence for these Nazi policies and practices found in the writings emanating from multiple disciplines" (1-2). In addition, she strives to "emphasise the climate of cruelty that pervaded not only the actions taken to implement the Holocaust by targeting reproduction and sexuality, but their sadistic and often misogynistic nature" (1-2). This undertaking requires the mobilization of a broad corpus of sources, including diaries, memoirs, survivor testimonies that she deftly interweaves with modern medical and psychological theories. Her background in both psychology and medicine is beneficial because of her ability to blend an analysis on the short and long-term physical and mental effects of the women and how these effects could intertwine, rather than solely focusing on one aspect.

The remainder of the book is divided into two main sections that consider the intersection of Nazi reproductive policy with women (both Jewish and non-Jewish) under Nazi rule. Part One: Pregnancy and Childbearing is divided into five chapters which are then broken down further into smaller sections covering topics such as eugenics, sterilization, motherhood, ghettos, concentration camps, and the medical profession. Part Two: Sexuality and Sexualized Abuse is divided into five chapters which are then broken down further into smaller sections covering topics such as love and sexuality and how they differed between Jews and Non-Jews, sexual humiliation, emotional abuse, rape, sexual abuse, and sexualized physical battery. 
While both Parts covered different topics, Chalmers focuses in each part on how Nazi ideals and actions were integrated into everyday society. For example, school children would be presented with math problems such as "The construction of a lunatic asylum costs 6 million RM. How many houses at 15,000 RM each could have been built with that amount," and the construction of state-controlled brothels $(25,154)$. Chalmers continuously references the "dehumanizing" of the Jewish population throughout the text to contextualize the experiences they had under the Nazi Regime further exhibiting the integration of Nazi ideals.

Chalmers' research extends across the intersections of gender, sexuality, and race. The majority of the text focuses on the experience of Jewish and non-Jewish women who lived under Nazism. Although she is careful not to equivocate the "hardships" faced by non-Jewish women with the "horrors faced by Jewish women for whom pregnancy, if detected, almost invariably spelled death (64)," Chalmers nonetheless demonstrates that non-Jewish were victims of Nazi policies as well such as when infertile women were encouraged to divorce their husbands to "free" him for a more reproductive mate or women who had their children abducted from them (3). Chalmers further considers the plight of homosexual men and women whose orientations were contrary to Nazi doctrine but who suffered differently at the hands of the regime. The study of Jewish men, who were likewise persecuted systematically under Nazism, allows Chalmers to paint a more complete picture of the ghetto, prison, and concentration camp experiences

The Epilogue helps readers understand the need for the usage of the graphic stories shared throughout the text. Chalmers states that "this book is not intended to desecrate the memory of the Holocaust or its victims, but rather to honour their memory by recognising the realities they faced" (248). Her text in no way appears to "desecrate" the memory of these victims, but with the graphic depictions featured throughout the text, one can see why she felt the need to include this statement.

Chalmers is successful in her endeavours to present her broad perspective and achieving her objectives. Overall, the text, while interdisciplinary in nature, is easy to comprehend. Chalmers does not overwhelm the reader with field-related jargon and the text is broken down into small easy-to-read chapters and sections within the two main parts. What some readers may find difficult is the overall graphic and descriptive nature of the text. Due to the subject matter, the text, especially within the second part, depicts horrific events involving sexual abuse, sexual brutality, and violence against adults and children. This is not a critique of the text, as it is important that 
readers are exposed to the realities of the female experience and leaving out the types of graphic depictions utilized by Chalmers aids in the "sweetening" of the Holocaust that she discusses in her epilogue (256). With that in mind, this text would be an asset for anyone wishing to educate themselves on women's varying experiences during the Holocaust, as well as anyone wanting to know more about sexuality in ghettos, prisons, and concentration camps. 